\title{
FILHOS ADOLESCENTES E A VIVÊNCIA DE SER MÃE NA CONTEMPORANEIDADE - UM ESTUDO DE CASO
}

Poliana Emerich Cordeiro ${ }^{1}$ Camila Cortellete Pereira da Silva ${ }^{2}$ Regiane da Silva Macuch $^{3}$ Rute Grossi Milani ${ }^{3}$

1 Psicóloga, especialista em Psicanálise: Teoria e Clínica pelo Centro Universitário Cesumar - UniCesumar - Maringá - Pr, Maringá - Paraná.

2 Psicóloga, mestranda em Promoção da Saúde, Centro Universitário Cesumar UniCesumar - Maringá - Paraná. camilacortellete@hotmail.com

3 Profa Dra do Programa de Mestrado em Promoção da Saúde do Centro Universitário Cesumar - UniCesumar, Bolsista de produtividade do Instituto Cesumar de Ciência, Tecnologia e Inovação - ICETI, Maringá (PR) - Maringá - Paraná

Recebido em: 22/09/2018 - Aprovado em: 23/11/2018 - Publicado em: 03/12/2018 DOI: 10.18677/EnciBio_2018B111

\begin{abstract}
A maternidade é uma experiência complexa para a maioria das mulheres, na qual, vários fatores podem facilitar ou dificultar seu exercício, dessa forma, o presente artigo descreve e analisa as vivências da função materna de três mães de filhos adolescentes. Trata-se de um estudo de caso realizado com um grupo de pais em uma instituição de apoio social. Foram realizadas entrevistas, baseadas em um roteiro de perguntas semiestruturado. Na sistematização e compreensão das respostas foi utilizada a análise de conteúdo, e para a discussão foi adotado o referencial psicanalítico. Os resultados evidenciaram que o exercício da função materna depende do tempo e do espaço no qual se insere, e que na atualidade assume algumas características peculiares, como o trabalho formal e a necessidade de sentir-se realizada pessoal e profissionalmente. Outro aspecto observado foi a influência que os modelos identificatórios, assim como as questões culturais e sociais exercem sobre a função materna. Quando os filhos chegam à adolescência, as mães passam a ter que reconsiderar sua experiência de maternidade. Conclui-se que as mulheres deste estudo de caso, embora tenham encontrado muitos desafios em conciliar os cuidados com os filhos adolescentes e demais tarefas, conseguiram exercer a função materna.
\end{abstract}

RESUMO

PALAVRAS-CHAVE: Adolescência; Maternidade; Relações familiares.

\section{ADOLESCENTS CHILDRENS AND THE EXPERIENCE OF BEING MOTHER IN CONTEMPORANEITY}

\section{ABSTRACT}

The maternity is a complex experience for the majority of women, in which several factors may facilitate or delay their exercise, so this article aims to describe and analyze the experiences of the maternal function from three mothers of adolescents. 
This is a case study with a group of parents headed by a social support institution. Interviews were conducted, based on a semi-structured questionnaire. The content analysis was used for the systematization and comprehension of the answers, and the psychoanalytical framework was adopted for the discussion. The results showed that the exercise of maternal function depends on the time and space in which it is inserted, and that at present it has some peculiar characteristics, such as formal working and the need to feel personally and professionally satisfied. Another aspect observed was the influence that the identificational models, as well as the cultural and social issues, exert on the maternal function. When children reach adolescence, mothers will have to reconsider their experience of motherhood. Thus, it is concluded that the exercise of maternity, however challenging, according to the women's in this case study, was able to exercise the maternal function.

KEYWORDS: Adolescence; Maternity; Family relation.

\section{INTRODUÇÃO}

No percurso dos estudos sobre a relação mãe-bebê, o papel da maternidade foi sendo ressignificado, como por exemplo, quanto ao reconhecimento de outras figuras importantes além da mãe, e a magnitude e o impacto do vínculo materno quando exercido pela mãe no desenvolvimento psíquico do bebê continua sendo fortemente reconhecido e estudado (CORRÊA; SERRALHA, 2015, GOMES et al., 2015, ANDRADE et al., 2017, ROHM; RADAELLI, 2017, GIORDANI et al, 2018).

A função materna, tão almejada, e por muitos considerada como inerente à mulher, é um fenômeno que envolve a aprendizagem de habilidades e competências (ANDRADE et al., 2017). De acordo com Rodriguez et al. (2017), a sociedade compreende os papéis de mãe e pai como algo natural, quando na realidade são construções sociais, nas quais, da mulher se espera a assistência e amparo material e emocional, enquanto ao homem concerne a figura castradora, de proibição.

O modelo familiar até os anos 50 baseava-se na complementariedade de papéis, em que o pai se responsabilizava pelo sustento do lar e à mulher ficavam reservadas as atividades referentes à casa e aos filhos (BORSA; NUNES, 2011). Mas, com as transformações econômicas e a entrada da mulher no mercado de trabalho, observou-se um impacto sobre o antigo modelo familiar, provocando uma redefinição dos papéis, de tal modo que a maternidade é ressignificada, e o foco central do desejo das mulheres não se limita mais em apenas ter filhos (KEHL, 2001).

Dessa forma, ocorreu uma crise nos papéis de "ser homem" e "ser mulher", aqueles desempenhados na sociedade, o que contribuiu para modificações na família nuclear. Outra característica, muitas atividades que cabiam à função materna ou paterna são divididas com terceiros. Assim sendo, observou-se que a patologia da família é que os pais e/ou educadores, em dívida para com a família nuclear do passado, não conseguem sustentar seu lugar de autoridade e responsabilidade na criação dos filhos (KEHL, 2001).

Por outro lado, crianças são investidas altamente, de forma narcísica, como única esperança de adultos desgarrados do seu próprio lugar como filhos e herdeiros de algum passado. Segundo Freud (1914), os pais investem de forma afetuosa no filho, pois este reativa as vivências do seu próprio narcisismo que eles renunciaram para se deparar com a vida adulta. Essa possibilidade do renascimento narcísico acontece, ao ser oferecido ao ego dos pais o lugar da imortalidade e perfeição por meio da criança. 
Segundo Szejer e Stewart (1997), ao ser gerada, a criança já está inserida numa história da qual ela fará parte e assumirá um lugar. Esse locus nascendi, composto pela história de antes do encontro, ou seja, de cada linhagem, a do pai e a da mãe, e também pelo projeto da gravidez.

Assim, primeiramente, um filho é o desejo de um homem e de uma mulher, e do encontro desses dois desejos resultará o nascimento de um terceiro, "o desejo de vida que vai se encarnar no corpo do filho" (SZEJER; STEWART, 1997), a partir disso vai nascer um projeto. Esse projeto, consciente ou não, também faz parte da pré-história do filho.

Szejer e Stewart (1997) colocam que o desejo de ter bebê não corresponde ao projeto de ser pais, pois quando se deseja um filho, ele será projetado no futuro, enquanto que ter um objetivo, o de ser pais, é projetar a si mesmo no futuro da criança. As autoras ainda falam que a maneira como cada um se coloca como mãe ou pai está relacionada aos modelos identificatórios que cada um teve.

Para Klein (1996b), são esses desejos experimentados na infância que contribuem para a força do amor que a mulher grávida sente em relação à criança crescendo dentro dela e da qual dará à luz. Nisso, é vista em ação o processo de identificação, que, segundo Laplanche e Pontalis (2001), constitui o mecanismo por meio do qual a criança assimila características das pessoas ao seu redor, a consequência da identificação com as figuras parentais implica na instalação de todos os valores morais destas figuras.

Winnicott (2000) vai dizer que no final da gestação a mulher entra num estado mental que se assemelha ao adoecimento, a fim de que a função materna possa ser exercida. Ele denomina este estado de "preocupação materno primária", o qual permite à mãe atingir progressivamente um grau de sensibilidade aumentada da capacidade de renunciar a excessos e envolvimentos externos e direcioná-los para a criança.

Este ambiente suficientemente bom no início da vida do bebê é proporcionado pela mãe pelo estado de identificação com ele, o que permite que ela esteja atenta às necessidades do seu filho. Assim, entra o que Winnicott (2000) fala a respeito da importância da função do "holding", no sentido de sustentação, ou seja, se a mãe segura afetivamente seu bebê, também lhe proporciona amparo, segurança, noção de existência e integração.

Conforme o filho cresce, a natureza da relação da mãe com o filho muda. Determinadas dificuldades nessas relações do passado podem interferir nos sentimentos que a mãe nutre pelo próprio filho. De acordo com Klein (1996b), a capacidade de se por no lugar da criança e encarar a situação de seu ponto de vista faz parte dessa atitude maternal. Portanto, essa habilidade está intimamente relacionada ao sentimento de culpa e impulso de reparação. A ausência dessa capacidade pode indicar um disfarce para os sentimentos de culpa muito fortes.

Para que a função materna consiga acompanhar o crescimento do filho e assim ser exercida de forma plena se faz necessário reconhecer o seu desenvolvimento e as mudanças decorrentes das fases do seu desenvolvimento. A passagem da infância para a vida adulta é traduzida por uma mudança de território e pela ruptura dos laços e dos investimentos do passado, transformando o que era familiar em algo estranho (GOMES, 2018). Essa estranheza pode gerar um estado de desamparo no adolescente, o qual, precisa lidar com novas questões, dentre elas, o seu novo corpo e o novo olhar nas relações com os outros. 
Entende-se que a adolescência pode ser vista como um ajuste complexo por parte da criança às mudanças físicas e emocionais. Ajuste que tem como implicação a busca por um novo sentido de "si-mesmo-mundo" (WADDELL, 2017).

Todas essas alterações contribuem para o afastamento do jovem do meio familiar, o mesmo passa a não conseguir perceber este ambiente como sendo suficiente para sustentar suas demandas e angustias. Dessa forma, o adolescente se apega a uma subcultura de grupos, quando os relacionamentos com os pares passam a desempenhar uma função de sustentação muito favorável (WADDELL, 2017). No entanto, Prioste (2016) afirma que o núcleo familiar não se torna obsoleto, mas passa a ter uma função de retaguarda, enquanto o meio social assume maior poder de influência.

A autoridade parental é o nome dado pelo psiquiatra Siegel (2016) a este apoio oferecido aos filhos, em que oferta-se um porto seguro, enquanto também estimula a exploração. Dessa forma, o vínculo possibilita a definição de limites, ao mesmo tempo em que respeita sua autonomia.

\footnotetext{
Fazemos o possível para fornecer os elementos básicos do vínculo, deixando nossos filhos serem vistos, sentirem-se protegidos, terem tranquilidade e se sentirem seguros. É desta base de vínculo seguro que os adolescentes podem então navegar as águas brancas e furiosas dessa tumultuada jornada com as melhores esperanças de equilíbrio e agilidade (SIEGEL, 2016, p. 38).
}

Outeiral (2008) também defende a ideia de que esse processo é doloroso tanto para os pais quanto para os adolescentes, e a forma como esses pais vivenciaram esse processo com seus próprios pais é essencial. Nessa fase, o adolescente inicia o processo de "independização" com o intuito de transformar os vínculos infantis em vínculos maduros e menos idealizados, exigindo dos pais uma postura de compreensão que, muitas vezes, se torna complicada em função da atitude da desvalorização dos filhos em relação a eles.

Desta forma, é comum o grupo familiar, como um todo, "adolescer" quando tem um filho tornando-se adolescente. Isso se deve ao fato de que os pais reativam seus elementos adolescentes e podem chegar a portar-se como um (OUTEIRAL, 2008). Neste contexto, objetivou-se neste artigo, compreender a função materna e como a mesma se dá com a chegada da adolescência dos filhos.

Participantes

\section{MATERIAL E MÉTODOS}

Três mulheres entre 30 e 40 anos, sendo duas casadas e uma divorciada. As mulheres residiam em uma cidade no interior do Paraná e todas atendiam aos critérios estabelecidos de inclusão na pesquisa: participação em um grupo de pais em uma instituição de apoio social e ter filhos entre 10 e 18 anos.

\section{Instrumento}

Para a coleta de dados foi elaborado previamente um roteiro semiestruturado de entrevista. Os aspectos abordados foram: compreensão das mães sobre função materna; sua relação com seus cuidadores quando ainda criança; gestação e mudanças em decorrência do nascimento do filho; o processo de se tornar mãe e a comparação da educação dos filhos quando pequenos e na adolescência. 
Procedimento de coleta e análise dos dados

A pesquisa obteve a aprovação do Comitê de Ética do Centro Universitário de Maringá, Cesumar, sob o parecer ํo 151/2011. Após o aceite, fez-se contato com três mulheres integrantes do grupo de pais coordenado por uma das pesquisadoras, tendo-se como intuito apresentar os objetivos e procedimentos da pesquisa. Ressaltou-se o compromisso quanto ao sigilo e à liberdade de retirada do consentimento a qualquer momento da pesquisa.

As três entrevistas aconteceram na residência das participantes, em datas previamente combinadas, onde se estabeleceu um setting apropriado, por meio da escolha de um ambiente reservado, de modo a garantir o sigilo das informações. As mães assinaram o Termo de Consentimento Livre Esclarecido, assentindo em participar das entrevistas.

Utilizou-se da Análise de Conteúdo de Bardin (2009), como forma de sistematização, análise e discussão dos dados obtidos. Após, os resultados foram interpretados com base no referencial teórico psicanalítico. Desta forma, com a análise de conteúdo buscou-se a compreensão do que é dito indiretamente por meio do conteúdo manifesto, possibilitando a compreensão dos seus significados.

\section{RESULTADOS E DISCUSSÃO}

Por meio da análise das entrevistas realizadas, propôs-se a divisão dos dados interpretados em duas categorias: 1) maternagem na contemporaneidade; 2) relação mãe-filho adolescente.

\section{A maternagem na contemporaneidade}

No discurso das mulheres foi possível observar aspectos característicos da configuração materna nos dias atuais, dentre eles, atenta-se para a busca da realização pessoal e da inserção no mercado de trabalho.

Nota-se um movimento cada vez mais frequente das mulheres abdicarem dos cuidados integrais de sua família, seja por suas ambições pessoais ou pela necessidade mantenedora. Em contrapartida, algumas atividades que antes eram delegadas especificadamente aos pais e mães, passam a ser atribuídas a terceiros, tais como, professores, babás, psicólogos, médicos. Ou ainda parentes próximos como avós paternos e maternos (KEHL, 2001). Com base nos dados analisados notam-se aspectos relacionados à problemática:

[...] comecei a trabalhar cedo, mas eu sempre quis estudar. Eu terminei o segundo grau e estava grávida dos gêmeos. Eu sempre quis estudar, não pude estudar, não foi fácil, então acho que com isso eu culpava um pouco a minha mãe entendeu?! Hoje minha cabeça é outra e eu entendo que não tem culpa, era a realidade da gente. Por isso que eu quero pros meus filhos, quero dar pra eles o que eu não tive.[...] M3

No discurso de M3, se percebe o desejo dela por persistir nos estudos, surgindo ainda uma responsabilização de sua mãe por "negar" a sua realização. Percebe-se que ela reexperimenta aspectos narcísicos ao postular que eles tenham o que a mesma não possuiu. Os termos desse contrato narcisista se assemelham ao que foi dito por Freud, nestes os pais reivindicam ao filho todos os privilégios que eles próprios tiveram de desistir. Tudo aquilo que possa limitar a felicidade ou o bem-estar do homem deve ser alvo de moratória: doença, morte, renúncia do prazer, 
restrições e leis não devem valer para os bebês, aspirando-os a condições que Freud (1914) denominou "Sua majestade o bebê".

Já em relação à experiência da maternidade, verifica-se uma grande influência dos seus modelos identificatórios, ou seja, segundo Klein (1996a), baseiase nas fantasias e vivências da menina durante a "fase feminina" do Complexo de Édipo precoce. Nessa fase, ela desenvolve uma relação fantasiosa com o corpo materno, do qual deseja se apoderar do conteúdo "bom" e atacar o conteúdo "mau". Essas fantasias despertam sentimentos de angústias e culpa, como, por exemplo, o medo de ter seu corpo destruído ou de não ter bebês. O nascimento do filho é a prova de que o interior de seu corpo se encontra ileso.

Outra questão levantada por Klein (1996b) é que para sair da situação edípica, a menina renuncia ao amor pelo pai, adiando o desejo pelo filho, a fim de manter o amor da mãe. Para Klein (1996a), os desejos experimentados na infância permanecem até a vida adulta e contribuem para a força do amor que a mulher direciona à criança. A gratificação de ter um filho no futuro alivia a dor da frustração sentida na infância e a realização adiada desse desejo também ajuda a tornar a mulher menos agressiva e a aumentar sua capacidade de amar.

[...] com a minha mãe a relação foi boa, assim a gente conversava, na medida do possível, mas não igual a outras mães que conversam tudo de mãe e filha. Com o meu pai a conversa era mínima possível, não tinha diálogo. Não abraçava, não beijava. [...] M2

M2 ao relatar sobre sua infância traz um certo distanciamento afetivo de seus pais, sendo percebido por ela como diferente do esperado da função parental "não igual a outras mães que conversam tudo de mãe e filha" (M2). Entretanto, ao verificar a relação da mesma com seu filho, nota-se a mesma dinâmica atuando:

[...] com meu menino eu sou mais brava, não sou de ficar abraçando, beijando ele, tipo assim dou carinho na hora em que tem que dar, mas eu sou mais rígida com ele. Agora com a minha filha não, até porque ela é pequena ainda né, porque nunca fez nada de errado, mas também se fizer vou começar a ser mais rígida também. Mas a gente se abraça, beija um pouquinho, porque ela que vem atrás da gente para abraçar e beijar. [...] M2

Quanto a este comportamento, entende-se que o tornar-se mãe sugere um investimento interior com a aceitação da herança parental, sendo possível continuar repetindo ou se tornar autor de um novo legado (RODRIGUEZ et al., 2017, ROHM; RADAELLI, 2017).

Observa-se ainda que a visão tradicionalista idealiza a maternidade, que segundo Gutman (2016), é socialmente esperado que as mulheres sejam amáveis, doces e tolerantes, em qualquer situação, seja social, profissional ou pessoal. Isto contribui para a construção idealizada de uma mãe perfeita, entretanto, a mesma complementa, dizendo que não é necessário que a mulher se torne abnegada ou professe um amor incondicional em cada situação que lhe seja apresentada.

A transformação e o aprendizado por meio das experiencias que a maternidade oferece, favorecem 0 desenvolvimento e crescimento pessoal, auxiliando ainda nas relações familiares. O discurso das mães mostra a influência que a maternidade teve sobre elas: 
[...] a gente amadurece né? A gente muda muito, e essa experiência de ter um filho faz a gente mudar de atitude, muda até o nosso jeito. [...] M1

[...] mudei, antigamente os outros falavam para mim e eu abaixava a cabeça, ficava quieta, eu era muito tímida, eu ainda sou, mas eu era muito tímida, hoje não. Depois que meu filho nasceu, você tem que procurar médico, defender seu filho, você começa a mudar teu jeito, pelo menos eu. Como se diz você tem que defender sua cria. A gente muda bastante. [...] M2

Conforme verificado nos relatos, compreende-se que a maternidade não é algo inerente ao feminino, ou seja, não é necessário que as mulheres ao gerarem seus bebês saibam prontamente como lidar, "como se houvesse um instinto que Ihes bastasse para serem mães perfeitas" (CORRÊA; SERRALHA, 2015). Pelo contrário, é por meio da experiência e da convivência com seus filhos que as mulheres desenvolvem a função materna satisfatoriamente.

\section{A relação mãe-filho adolescente}

A condição de sustentar as emoções e os sentimentos dos filhos é um exercício complexo, sendo necessário uma boa disponibilidade interna. Esta capacidade é colocada à prova quando os mesmos atingem a adolescência, pois nesse período eles "tendem a se afastar dos pais e a se libertarem até certo ponto de sua velha ligação com eles" (KLEIN, 1996b, p. 360).

Com o crescimento do filho, atributos e aptidões vão sendo desenvolvidos e modificados na função parental, em um movimento de crescente alteração que vai mudando de acordo com o desenvolvimento das mesmas (BUSTAMANTE; SANTOS, 2015).

No relato das mães entrevistadas, verifica-se a dificuldade destas em lidar com seus filhos adolescentes. Para poder iniciar esse processo de "independização", o jovem precisa "desvalorizar" seu núcleo familiar, com isso, o adolescente consegue sentir que pode se distanciar sem ter o sentimento de perda. Dessa forma, espera-se que os pais consigam ter capacidade de "moratória", ou seja, consigam acolher e compreender os comportamentos assumidos pelo adolescente, até que o mesmo tenha mais maturidade e assim, melhores condições de perceber seus pais como são, sem idealizá-los ou denegrí-los. Pode-se verificar no discurso de M1 e M2 que ambas possuem dificuldade em assumir este papel de moratória:

[...] Que nem se fala filho criado dá trabalho dobrado, porque quando é mais novinho, você fala, ele obedece, se não obedece dá uns puxãozinho de orelha, fala é "assim, assim, assado", agora depois que pega uma idade já não tem como você fazer mais nada. [...] $O$ adolescente ele vem pra te desafiar mais e às vezes eu me sinto mal, tipo assim será que eu não tenho autoridade, eu não me sinto assim como aquela mãe que tem aquela autoridade. [...] M1

[...] Agora eu vejo que bebezinho é mais fácil de cuidar do que uma criança grande, porque grande você fala e ele responde. Você fala 10 vezes e ele (o adolescente) tá fazendo a mesma coisa. Bebê não, você cuida, você dá banho, você dá mamá, e coloca ali ele fica quietinho. Chora de vez em quando. [...] M2 
Nota-se que a autoridade tem sido um tema delicado, em relação à maternidade, pois as mães relatam não serem ouvidas por seus filhos, comportamento este que vem ao encontro com o que tem sido proliferado pela mídia, na qual, o adolescente é posto como protagonista dos cenários de transgressões, rebeldias ou ainda pela indiferença (GOMES, 2018). Entretanto, para Waddell (2017), esse processo representa uma forma de processar a dor, a confusão e o conflito mental, ou seja, há uma tendência em expulsar a dor, cenário recorrente na tendência do jovem de "atuar" conflitos internos no lugar de buscar resolvê-los.

[...] A adolescência da minha filha mais velha foi bem tranquila. Porque ela não me deu trabalho, ela foi bem tranquila, às vezes tava meio estressada que mal falava com a gente, tava emburrada ficava lá no canto dela lá, mas nunca foi de dar trabalho assim, como eu vejo muitas adolescentes dando bastante trabalho. Com ela eu não tive muita dor de cabeça não [...] M3

Já no relato de M3, um comportamento visto por ela como adequado ou até mesmo ideal para um adolescente, pode representar uma dificuldade em expressar um impasse interno, visto que a solidão, a ausência de questionamentos e de experimentações podem indicar um fracasso de projeção, que apesar de doloroso, precisa ser realizado (WADDELL, 2017).

Dessa forma, entende-se que a função materna exige da mulher as condições necessárias para a realização da continência e sustentação das angústias dos filhos, entretanto, para realizar essa tarefa se faz necessário que a mãe tenha disponibilidade interna para exercê-la. E quando os filhos chegam à adolescência,os pais deparam-se com outro agravante, atitudes de oposição colocam em cheque a autoridade destes, passando a exigir dos mesmos um comportamento ainda mais compreensivo e acolhedor. Outeiral (2008) corrobora este pensamento quando afirma que nesse período é necessário ter tolerância, uma tarefa desafiadora, mas imprescindível para que o adolescente consiga reformular seus vínculos familiares e com a sociedade, por meio de um modelo mais maduro.

\section{CONCLUSÃO}

Identifica-se neste artigo a influência de diversos fatores sob o exercício da função materna. Atualmente a maternidade tem assumido novas formulações, como a participação das mulheres no mercado de trabalho, tendo esta, possivelmente influenciado na divisão da função com terceiros. Por meio dos resultados obtidos percebe-se que a maternidade não pode ser imposta como algo inato da mulher, uma vez que depende de fatores sociais, culturais e pessoais de cada mulher, logo, tornar-se mãe é uma função em construção e envolve aprendizado.

A experiência de ser mãe é caracterizada pela sua complexidade, sendo repleta de conflitos, angustias, mas ao mesmo tempo, podendo ser um momento de muita alegria e gratificações. Desta forma, por meio das vivências, o exercício da função materna possibilita o crescimento pessoal.

A maternidade passa a exigir da mulher algumas atitudes capazes de dar sustentação e suporte aos seus filhos. O holding e a continência são exemplos da necessária disposição interna, por parte da mãe, para que ela possa exercer adequadamente a maternidade.

Nota-se que quando os filhos entram na fase da adolescência essa tarefa se torna ainda mais desafiadora, demandando uma atitude de maior compreensão 
materna num período em que o adolescente vem a desafiá-las. Consequentemente, todas essas questões têm repercussão na relação mãe e filho, e, dependendo da forma como cada mulher lida com esses conteúdos, pode dar espaço para o surgimento de novas angustias ou favorecer o vínculo e consequentemente, o devido suporte para o crescimento dos filhos.

Dessa forma, conclui-se que por mais desafiadora que a função materna seja, as mulheres desta pesquisa conseguiram ser mães para esses seus filhos, assumindo essa função.

\section{REFERÊNCIAS}

ANDRADE, C. J.; BACCELLI, M. S.; BENINCASA, M. O vínculo mãe-bebê no período de puerpério: uma análise winnicottiana. Vínculo - Revista do NESME, São Paulo, v. 14, n. 1, p. 1-13, 2017. Disponível em $<$ http://pepsic.bvsalud.org/scielo.php?script=sci_arttext\&pid=S1806$24902017000100004 \&$ Ing=pt\&nrm=iso $>$. acesso em 30 mar. 2018.

BARDIN, L. Análise de conteúdo. Lisboa: Edições 70, 2009.

BUSTAMANTE, V.; SANTOS, I. Arranjos familiares e possibilidades terapêuticas em um serviço de saúde mental infantil. Pensando famílias, Porto Alegre, v. 19, n. 2, p. 115-131, dez. $2015 . \quad$ Disponível em <http://pepsic.bvsalud.org/scielo.php?script=sci_arttext\&pid=S1679494X2015000200010\&lng=pt\&nrm=iso > . acesso em 30 mar. 2018.

CORREA, F. P.; SERRALHA, C. A. A depressão pós-parto e a figura materna: uma análise retrospectiva e contextual. Acta Colombiana de Psicologia, Bogotá, v. 18, n. 1, p. 113-123, Jan. 2015. Disponível em: http://www.scielo.org.co/scielo.php?script=sci_arttext\&pid=S0123-

91552015000100011\&lng=en\&nrm=iso. Acesso em 30 Mar. 2018. http://dx.doi.org/10.14718/ACP.2015.18.1.11.

FREUD, S. Introdução ao narcisismo (1914). São Paulo: Companhia das Letras, v. 12, p. 13-50, 2010.

GIORDANI, R. C. F.; PICCOLI, D.; BEZERRA, I.; ALMEIDA, C. C. B. Maternidade e amamentação: identidade, corpo e gênero. Ciência \& saúde coletiva, Rio de Janeiro , v. 23, n. 8, p. 2731-2739, ago. 2018. Disponível em $<$ http://www.scielo.br/scielo.php?script=sci_arttext\&pid=S1413-

81232018000802731\&lng=pt\&nrm=iso >. acessos em 02 Set. 2018. http://dx.doi.org/10.1590/1413-81232018238.14612016

GOMES, A. G.; MARIN, A. H.; PICCININI, C. A.; LOPES, R. C. S. Expectativas e sentimentos de gestantes solteiras em relação aos seus bebês. Temas em psicologia, Ribeirão Preto, v. 23, n. 2, p. 399-411, jun. 2015. Disponível em: http://pepsic.bvsalud.org/scielo.php?script=sci_arttext\&pid=S1413-

389X2015000200011\&lng=pt\&nrm=iso. Acesso em 30 mar. 2018. http://dx.doi.org/10.9788/TP2015.2-12. 
GOMES, V. R. R. Adolescentes na contemporaneidade: desamparo e laços fragilizados em meio aos ideais da sociedade de consumo. Rio de Janeiro: Gramma, 2018.

GUTMAN, L. A maternidade e o encontro com a própria sombra. Rio de Janeiro: Best Seller, 2016.

KEHL, M. R. Lugares do feminino e do masculino na família. In: COMPARATO, M. C. M.; MONTEIRO, D. S. F. (Org). A criança na contemporaneidade e a psicanálise. Volume I. São Paulo: Casa do Psicólogo, cap. 2, p. 29-38, 2001.

KLEIN, M. Estágios iniciais do conflito edipiano (1928). In: Amor, culpa e reparação e outros trabalhos (1921-1945). Rio de Janeiro: Imago, 1996a.

KLEIN, M. Amor, culpa e reparação (1937). In: Amor, culpa e reparação e outros trabalhos (1921-1945). Rio de Janeiro: Imago, 1996b.

LAPLANCHE, J.; PONTALIS, J. Vocabulário de psicanálise. 4. ed. São Paulo: Martins Fontes, 2001.

BORSA, J. C.; NUNES, M. L. T. Aspectos psicossociais da parentalidade: O papel de homens e mulheres na família nuclear. Psicologia Argumento, [S.I.], v. 29, n. 64, nov. 2011. ISSN 1980-5942. Disponível em: https://periodicos.pucpr.br/index.php/psicologiaargumento/article/view/19835. Acesso em: 31 mar. 2018.

OUTEIRAL, J. Adolescer: estudos revisados sobre adolescência. 3. ed. Rio de Janeiro: Revinter, 2008.

PRIOSTE, C. $O$ adolescente e a internet: laços e embaraços no mundo virtual. São Paulo: editora da Universidade de São Paulo, Fapesp, 2016.

RODRIGUEZ, B. C.; GOMES, I. C.; OLIVEIRA, D. P. Família e nomeação na contemporaneidade: uma reflexão psicanalítica. Estudos Interdisciplinares em Psicologia, Londrina, v. 8, n. 1, p.135-150, jun. 2017 Disponivel em: http://www.uel.br/revistas/uel/index.php/eip/article/view/25914/20034. Acesso em: 28 de mar. 2018 DOI: http://dx.doi.org/10.5433/2236-6407.2017v8n1p135

ROHM, T; RADAELLI, J. A Relação mãe-criança e a feminilidade. Psicologia Argumento, [S.I.], v. 34, n. 85, nov. 2017. ISSN 1980-5942. Disponível em: https://periodicos.pucpr.br/index.php/psicologiaargumento/article/view/23316/22436 Acesso em: 31 mar. 2018.doi:http://dx.doi.org/10.7213/psicol.argum.34.085.AO07.

SIEGEL, D. J. Cérebro adolescente: o grande potencial, a coragem e a criatividade da mente dos 12 aos 24 anos. São Paulo: nVersos, 2016.

SZEJER, M.; STEWART, R. Nove meses na vida da mulher: uma abordagem psicanalítica da gravidez e do nascimento. São Paulo: Casa do Psicólogo, 1997. 
WADDELL, M. Vida interior: psicanálise e desenvolvimento da personalidade. São Paulo: Blucher, 2017.

WINNICOTT, D. Da pediatria à psicanálise. Rio de Janeiro: Imago, 2000. 